\title{
Global expansion of covid19 pandemic is driven by population size and airport connections
}

\author{
Marco Tulio Pacheco Coelho ${ }^{\text {Corresp., } 1}{ }^{1}$, João Fabrício Mota Rodrigues ${ }^{1}$, Anderson Matos Medina ${ }^{2}$, Paulo Scalco ${ }^{3}$, Levi \\ Carina Terribile ${ }^{4}$, Bruno Vilela ${ }^{2}$, José Alexandre Felizola Diniz-Filho ${ }^{1}$, Ricardo Dobrovolski ${ }^{2}$ \\ 1 Departamento de Ecologia, Universidade Federal de Goiás, Goiânia, GO, Brazil \\ 2 Instituto de Biologia, Universidade Federal da Bahia, Salvador, BA, Brazil \\ 3 Faculdade de Administração, Economia, Ciências Contábeis (FACE), Universidade Federal de Goiás, Goiânia, GO, Brasil \\ 4 Laboratório de Macroecologia, Universidade Federal de Jataí, Jataí, GO, Brasil \\ Corresponding Author: Marco Tulio Pacheco Coelho \\ Email address: marcotpcoelho@gmail.com
}

The pandemic state of COVID-19 caused by the SARS CoV-2 put the world in quarantine, led to hundreds of thousands of deaths and is causing an unprecedented economic crisis. However, COVID-19 is spreading in different rates at different countries. Here, we tested the effect of three classes of predictors, i.e., socioeconomic, climatic and transport, on the rate of daily increase of COVID-19 on its exponential phase. We found that population size and global connections, represented by countries' importance in the global air transportation network, are the main explanations for the early growth rate of COVID-19 in different countries. Climate and socioeconomics had no significant effect in this big picture analysis. Our results indicate that the current claims that the growth rate of COVID-19 may be lower in warmer and humid countries should be taken very carefully, risking to disturb well-established and effective policy of social isolation that may help to avoid higher mortality rates due to the collapse of national health systems. 


\section{Global expansion of covid19 pandemic is driven by population size}

\section{2 and airport connections}

4 Marco Túlio Pacheco Coelho ${ }^{1}$, João Fabricio Mota Rodrigues ${ }^{1}$, Anderson Matos

5 Medina $^{2}$, Paulo Scalco ${ }^{3}$, Levi Carina Terribile ${ }^{4}$, Bruno Vilela ${ }^{2}$, José Alexandre

6 Felizola Diniz-Filho ${ }^{1} \&$ Ricardo Dobrovolski ${ }^{2}$

7

81 Departamento de Ecologia, Universidade Federal de Goiás, Goiânia, Goiás, Brazil.

92 Instituto de Biologia, Universidade Federal da Bahia, Salvador, BA, Brazil

10 3. Faculdade de Administração, Economia, Ciências Contábeis (FACE), Universidade Federal

11 de Goiás, Goiânia, Goiás, Brazil.

12 4. Laboratório de Macroecologia, Universidade Federal de Jataí, Jataí, GO, Brazil

Corresponding Author:

Marco Túlio Pacheco Coelho

Departamento de Ecologia, Universidade Federal de Goiás, Goiânia, Goiás, Brazil 


\section{Abstract}

The pandemic state of COVID-19 caused by the SARS CoV-2 put the world in

24 quarantine, led to hundreds of thousands of deaths and is causing an unprecedented economic

25 crisis. However, COVID-19 is spreading in different rates at different countries. Here, we tested

26 the effect of three classes of predictors, i.e., socioeconomic, climatic and transport, on the rate of

27 daily increase of COVID-19 on its exponential phase. We found that population size and global

28 connections, represented by countries' importance in the global air transportation network, are

29 the main explanations for the early growth rate of COVID-19 in different countries. Climate and

30 socioeconomics had no significant effect in this big picture analysis. Our results indicate that the

31 current claims that the growth rate of COVID-19 may be lower in warmer and humid countries

32 should be taken very carefully, risking to disturb well-established and effective policy of social

33 isolation that may help to avoid higher mortality rates due to the collapse of national health

34 systems.

35

36 


\section{Introduction}

With the worldwide spread of the novel Coronavirus Disease 2019 (COVID-19), caused by the SARS-CoV-2 virus, we are experiencing a declared pandemic. One of the largest preoccupations about this new virus is its notable ability to spread given the absence of any effective treatment, vaccine, and immunity in human populations. Epidemiologists quantify the ability of infectious agents to spread by estimating the basic reproduction number $(R 0)$ statistic (Delamater et al., 2019), which measures the average number of people each contagious person infects. The new coronavirus is transmitting at an average $R 0$ between 2.7 and 3.2 (Billah et al. 2020, Liu et al. 2020), which is greater than seasonal influenza viruses that spread every year around the planet (median $R 0$ of 1.28, Biggerstaff et al., 2014). To anticipate the timing and magnitude of public interventions and mitigate the adverse consequences on public health and economy, understanding the factors associated with the survival and transmission of SARS-CoV2 is urgent.

Because previous experimental (Lowen et al., 2007), epidemiological (Shaman et al., 2010, Barreca \& Shimshack 2012), and modeling (Zuk et al., 2009) studies show the critical role of temperature and humidity on the survival and transmission of viruses, recent studies are testing the effect of environmental variables on SARS-CoV-2 (Wang et al., 2020, Sajadi et al., 2020, Harbert et al. 2020, Araújo et al. 2020) and forecasting monthly scenarios of the spread of the new virus based on climate suitability (Araújo \& Naimi 2020, but see Carlson et al. 2020). Although temperature and humidity affect the spread and survival of other coronaviruses (i.e., SARS-CoV and MERS-CoV, Tan et al., 2005, Chan et al., 2011, Doremalen et al., 2013, Gaunt et al., 2010) using the current occurrences of SARS-CoV-2 cases to build correlative climatic suitability models without considering connectivity among different locations and 
60 socioeconomic conditions might be inadequate, especially considering that the definition of

61 climatic niche of a respiratory virus, transmitted from person to person, is very challenging

62 (Carlson et al. 2020).

63 Many factors might influence the distribution of diseases at different spatial scales.

64 Climate might affect the spread of viruses given its known effect on biological processes that

65 influences many biogeographical patterns, including the distribution of diseases and human

66 behavior (e.g., Murray et al., 2018). Geographic distance represents the geographical space

67 where the disease spread following the distribution of hosts and also explains biogeographic

68 patterns (Pulin 2003, Nekola \& White 2004, Warren 2014). Socioeconomic characteristics of

69 countries include population size, which represent a key epidemiological parameter that

70 determines the rate and reach of pandemics (Grassly \& Fraser 2008) and other variables that

71 represent a proxy for the ability to identify and treat infected people and for the governability

72 necessary to make fast political decision and avoid the spread of new diseases (Adler \& Newman

73 2003, Gilbert et al. 2020, Khalatbari-Soltani et al. 2020). Finally, the global transportation

74 network might surpass other factors as it can reduce the relative importance of geographic

75 distance and facilitate the spread of viruses and their vectors (Brockmann \& Helbing 2013,

76 Pybus et al., 2015). According to the International Air Transport Association (2019) more than 4

77 billion passengers made international travels in 2018. This amount of travelers reaching most of

78 our planet's surface represents a human niche construction (Boivin et al., 2016) that facilitates

79 the global spread of viruses and vectors (Brockmann \& Helbing 2013) in the same way it

80 facilitated the spread of invasive species and domesticated animals over modern human history

81 (Boiving et al., 2016). 
The spread of SARS-CoV-2 from central China to other locations might be strongly

83

84

85

86

87

88

89

90

91

associated with inter-country connections, which might largely surpass the effect of climate suitability. Thus, at this point of the pandemic, there is still a distributional disequilibrium that can generate very biased predictions based on climatic correlative modeling (De Marco et al., 2008). Here we used an alternative macroecological approach (Burnside et al., 2012), based on the geographical patterns of early growth rates of the disease at country level, to investigate the drivers of the growth rates of COVID-19 in its exponential phase. We studied the effect of environment, socioeconomic, and global transportation controlling for spatial autocorrelation that could bias model significance. By analyzing these factors, we show that the exponential growth rate of COVID-19 at global scale is explained mainly by population size and country's importance in the global transportation network.

\section{Material \& Methods}

We collected the number of detected cases of COVID-19 per day from the John Hopkins (Dong et al., 2020) and European Centre for Disease Prevention and Control (ECDC, 2020). For each country we only used the "exponential" portion of the time series data (i.e. number of new people infected per day) and excluded days after stabilization or decrease in total number of cases (e.g. Fig S1). Although we are aware that more complex logistic-like curves of growing cases are expected, simpler exponential growth rates are a simpler description of the expansion in early phases and in practice coefficients are indistinguishable from logistic when $\mathrm{N}<<\mathrm{K}$. This procedure is also important to guarantee that only the early phase of the disease is analysed given that stabilization and decreasing in growth rates are caused both by natural population dynamics (following a logistic model) and by the interplay of different interventions made by each country, 
105

106

107

108

109

110

111

112

113

114

115

116

117

118

119

120

121

122

123

124

125

126

127

such as political and legal reinforcements of social distancing measures, including lockdown, obligatory mask use and others (Chinazzi et al. 2020, Kraemer et al. 2020, Zhang et al. 2020).

Time series data are available for 204 countries, for which 65 had more than 100 cases recorded and for which time series had at least 30 days of exponential growth after the $100^{\text {th }}$ case. We also performed the analysis considering countries with more than 50 cases, but it did not qualitatively change our results. Thus, we only show the results for countries with more than 100 cases. We empirically modelled each time series using an exponential growth model for each country and calculated both the intrinsic growth rate (r) and the regression coefficient of the $\log$ growth series to be used as the response variable in our models. Because both were highly correlated (Pearson's $r=0.97$, Fig S2), we used only the regression coefficient to represent the growth rate of COVID-19 in our study.

To investigate potential correlates of the virus growth rate, we downloaded climatic and socioeconomic data of each country. We used climatic data represented by monthly average minimum and maximum temperature $\left({ }^{\circ} \mathrm{C}\right)$ and total precipitation $(\mathrm{mm})$ retrieved from the WorldClim database (https://www.worldclim.org) (Fick \& Hijmans 2017). We used monthly data for 2018, the most recent year available in WorldClim (Fick \& Hijmans 2017, Harris et al. 2014). We extracted climatic data from the months of January, February, March, and December to represent the climatic conditions of the winter season in the Northern Hemisphere and the summer season in the Southern Hemisphere. Temperature and precipitation are used here because of their critical role on virus transmissions (Lowen et al., 2007, Shaman et al., 2010, Barreca \& Shimshack 2012, Zuk et al., 2009) and because of the recent investigations about its potential effect on the spread of COVID-19 (Araújo \& Naimi 2020, Harbert et al. 2020). In addition, the predefined time period, winter in the northern hemisphere and summer in the 
128 southern hemisphere, represents the seasons in which the virus started to spread in the different

129 hemispheres. From these data, we computed the mean value of climatic variables across each

130 country. Finally, minimum, and maximum temperatures were combined to estimate monthly

131 mean temperature for December, January, February, and March, which was used in the model

132 along with total precipitation for the same months. However, using different combinations of

133 these variables (i.e., using means of minimum or maximum temperatures, as well as minimum or

134 maximum for each month) did not qualitatively affect our results.

135 We extracted socioeconomic data for each country. Human Development Index (HDI)

136 rank, mean number of school years in 2015, gross national income (GNI) per capita in 2018

137 population size in 2015 and average annual population growth rate between $2010-2015$ were

138 used in our study and downloaded from the United Nations database

139 (http://hdr.undp.org/en/data) and from the World Inequality Database (https://wid.world). We

140 also obtained a mean value of investments in health care by averaging the annual investments in

141 health care in each country between 2005-2015 obtained from the World Health Organization

142 database (http://apps.who.int/gho/data/node.home). Due to the strong collinearity among some of 143 these predictors, HDI rank and mean number of school years were removed from our final 144 model.

145 Finally, we also downloaded air transportation data from the OpenFlights (2014) database 146 regarding the airports of the world, which informs where each airport is located including 147 country location (7,834 airports), and whether there is a direct flight connecting the airports 148 (67,663 connections). We checked the Openfligths database to make the airports and connections compatible by including missing or fixing airport codes and removing six unidentified airport connections resulting in a total of 7,834 airports and 67,657 connections. We used this 
151 information to build an air transportation network that reflects the existence of a direct flight

152 between the airports while considering the direction of the flight. Thus, the airport network is a

153 unipartite, binary, and directed graph where airports are nodes and flights are links (Fig 1, Fig

154 S3). In the following step, we collapsed the airports' network into a country-level network using

155 the country information to merge all the airports located in a country in a single node (e.g.,

156 United States had 613 airports that were merged in a single vertex representing the country). The

157 country-level network (Fig 1, Fig S3) is a directed weighted graph where the links are the

158 number of connections between 226 countries which is collapsed for the 65 countries that had

159 more than 100 cases and for which time series data had at least 30 days after the $100^{\text {th }}$ case .

160 Afterward, we measured the countries centrality in the network using the Eigenvector Centrality

161 (Bonacich, 1987), that weights the importance of a country in the network considering the

162 number of connections with other countries and how well connected these countries are to other

163 countries - indirect connections. All networks analyses were generated using package igraph

164 (Csardi \& Nepusz, 2006).

165 We evaluated the relationship between the predictors (climatic, socioeconomic and

166 transport data) and our growth rate parameter (the regression coefficient of the log-transformed

167 growth series) using a standard multiple regression (OLS) considering the distribution of the

168 original predictors as well as the normality of residuals. Moreover, OLS residuals were

169 inspected to evaluate the existence of spatial autocorrelation that could upward bias the

170 significance of predictor variables on the model using Moran's correlograms (Legendre \&

171 Legendre 2013). Prior to the analysis, we applied logarithmic (mean precipitation, total

172 population size, and network centrality) and square root (mean health investments)

173 transformations to the data to approximate a normal distribution. 


\section{Results}

The models used to estimate COVID-19 growth rate on different countries showed an

177

178

179

180

181

182

183

184

185

186

187

188

189

190

191

192

193

194

195

196

average $\mathrm{R}^{2}$ of $0.91(\mathrm{SD}=0.04)$, varying from 0.78 to 0.99 , indicating an overall excellent performance on estimating growth rates. The geographical patterns in the growth rates of COVID-19 cases do not show a clear trend, at least in terms of latitudinal variation, that would suggest a climatic effect at macroecological scale (Fig. 2).

We build one model including only climate, which explained only $0.03 \%$ of the variation on growth rates. When we added socioeconomic variables, the $\mathrm{R}^{2}$ increased to $53.95 \%$. Finally, when we added country centrality (i.e. country importance in the global transportation network) as a predictor, the $\mathrm{R}^{2}$ increased to $59.56 \%$. In this model, only population size and country centrality had positive and significant effects (Fig 3, Table 1). Thus, exponential growth rates increased strongly in response to countries population size and their importance in the transportation network (Table 1, Fig 3). Statistical coefficients were not upward biased by spatial autocorrelation.

\section{Discussion}

At global scale, Gross National Income, annual population growth, investment in healthcare, mean temperature and mean precipitation had no significant effect on the exponential phase of COVID-19. Population size and countries importance in the global transportation network have key roles on the growth rate of COVID-19.

Population size is a critical factor in epidemiological outbreaks and faster growths of COVID-19 were reported in cities with larger populations (Stier et al. 2020). Here, we observe 
197 the same pattern at country level. Faster spread in regions with larger populations have been

198 explained by the interaction of frequent trades and people exchanges, and the difficulty to control

199 early outbreaks within larger populations (Jaffe et al. 2020, Harbert et al. 2020, Stier et al. 2020).

200 Because of the multiple infection routes and faster spread in larger populations, recent

201 discussions emphasize the need to implement more aggressive social distancing policies in

202 regions with larger populations (Stier et al. 2020). However, not only population size explains

203 the exponential growth of COVID-19 in different countries but also how central a country is in

204 the global transportation network.

205 Network centrality measures are widely used to discover distinguished nodes on

206 networks, including epidemiological networks (e.g., Madotto \& Liu 2016). Our findings

207 reinforce the importance of propagule pressure on disease dissemination (Tian et al., 2017,

208 Chinazzi et al., 2020). Aerial transportation is an important predictor of COVID-19

209 dissemination in China (Kraemer et al., 2020), Brazil (Ribeiro et al., 2020), and Mexico (Dátillo

210 et al., 2020). Countries characterized by higher centrality in the global transportation network

211 represent distinguished nodes, in terms of how well they are directly and indirectly connected to

212 other countries. These countries are the ones that are more prone to receive higher number of

213 infected individuals in different regions of their territory, which can potentially contribute to the

214 velocity of the initial spread of the disease.

215 The rapid international spread of the severe acute respiratory syndrome (SARS) from

2162002 to 2003 led to extensively assessing entry screening measures at international borders of

217 some countries (Bell et al., 2003, John et al., 2017). However, it is important to note that SARS-

218 CoV-2 can spread from pre-symptomatic and asymptomatic individuals (Gandhi et al. 2020, Bai

219 et al. 2020). Thus, entry screening measures at international borders might be only partially 
220 effective to identify symptomatic individuals, but not effective to stop de disease at international

221 borders. Even for diseases that could be stopped by identifying symptomatic travellers, there is

222 no consensus of the effective and accurate tools to be used in airports across the globe (Sun et al.,

223 2017). Finally, how effective airports closures were in different countries to decrease or stabilize

224 the spread of COVID-19 still needs to be tested in different countries and is beyond the scope of

225 this paper. However, after local transmissions are identified, we would expect that airport

226 closures are less effective than any other measure taken by governments, such as increasing

227 social distancing, tracking and isolating infected individuals (see Chinazzi et al. 2020).

228 When discussing and modelling the effect of climate on SARS CoV-2 it is important to

229 remember that modern human society is a complex system composed by strongly connected

230 societies that are all susceptible to rare events. It is also critical to consider the negative

231 correlations between climate and local or regional socioeconomic conditions (i.e., inadequate

232 sanitary conditions and poor nutritional conditions) that could easily counteract any potential

233 climatic effect at local scales, such as lower survival rates of viruses exposed to high humidity,

234 temperatures and high UV irradiation (Wang et al., 2020, Duan et al., 2003). Our analyses call

235 attention to the case of Brazil, a well-connected and populated tropical country that presents one

236 of the highest increase rates of COVID-19 in its exponential phase. If decision makers consider

237 yet unsupported claims that growth rates of COVID-19 in its exponential phase might be lower

238 in warmer and humid countries, we might observe terrible scenarios unrolling in well-connected

239 and populated countries independent of their climatic conditions.

241 Conclusions 
network have key roles on the initial growth rate of COVID-19. We do not expect that our results

244

245

246

247

248

249

250

251

252

253

254

255

256

257

258

259

260

261

262

263

264

265

266

using a macroecological approach at a global scale would have a definitive effect on decisionmaking in terms of public health in any particular country, province, or city.

However, we call the attention for the absence of effects of climatic variables on the exponential phase of COVID-19 that is surpassed by how distinguished a country is in the air transportation network and by their population size. Thus, claims that the growth of COVID-19 might be lower in warmer and humid countries based on climate suitability models should be taken very carefully, risking to disturb well-established and effective policy of social isolation that may help to avoid higher mortality rates due to the collapse in national health systems.

\section{Acknowledgments}

This paper was developed in the context of the human macroecology project in the National Institute of Science and Technology (INCT) in Ecology, Evolution and Biodiversity Conservation, supported by CNPq (grant 465610/2014-5) and FAPEG (grant 201810267000023). JAFDF, RD, LCT are also supported by CNPq productivity scholarships. We thank Thiago F. Rangel, André Menegotto, Robert D. Morris, Marcus Cianciaruso, Diogo Provete and Blas M. Benito for their constructive comments on the manuscript.

\section{References}

Adler NE, Newman K. 2002. Socioeconomic disparities in health: Pathways and policies. Health Affairs 21:60-76. DOI: 10.1377/hlthaff.21.2.60. 
267

268

269

270

271

272

273

274

275

276

277

278

279

280

281

282

283

284

285

286

287

288

289

290

291

292

293

294

295

296

297

298

299

300

301

302

303

304

305

306

307

308

309

310

311
Araujo MB, Naimi B. 2020 Spread of SARS-CoV-2 Coronavirus likely to be constrained by climate. medRxiv , 2020.03.12.20034728. (doi:10.1101/2020.03.12.20034728)

Bai Y, Yao L, Wei T, Tian F, Jin D-Y, Chen L, Wang M. 2020. Presumed Asymptomatic Carrier Transmission of COVID-19. JAMA 323:1406-1407. DOI: 10.1001/jama.2020.2565.

Barreca AI, Shimshack JP. 2012 Absolute humidity, temperature, and influenza mortality: 30 years of county-level evidence from the united states. Am. J. Epidemiol. 176, 114-122. (doi:10.1093/aje/kws259)

Bell DM et al. 2004 Public health interventions and SARS spread, 2003. Emerg. Infect. Dis. 10, 1900-1906. (doi:10.3201/eid1011.040729)

Biggerstaff M, Cauchemez S, Reed C, Gambhir M, Finelli L. 2014 Estimates of the reproduction number for seasonal, pandemic, and zoonotic influenza: A systematic review of the literature. BMC Infect. Dis. 14, 1-20. (doi:10.1186/1471-2334-14-480)

Billah MA, Miah MM, Khan MN. 2020. Reproductive number of COVID-19: A systematic review and meta-analysis based on global level evidence. medRxiv:2020.05.23.20111021. DOI: $10.1101 / 2020.05 .23 .20111021$.

Bitar D. , Goubar A. DJC. 2009 International travels and fever screening during epidemics: a literature review on the effectiveness and potential use of non-contact infrared thermometers. Euro Surveill 14, pii=19115.

Boivin NL, Zeder MA, Fuller DQ, Crowther A, Larson G, Erlandson JM, Denhami T, Petraglia MD. 2016 Ecological consequences of human niche construction: Examining long-term anthropogenic shaping of global species distributions. Proc. Natl. Acad. Sci. U. S. A. 113, 6388-6396. (doi:10.1073/pnas.1525200113)

Bonacich P. 1987 Power and Centrality: A Family of Measures. Am. J. Sociol. 92, 1170-1182. (doi:10.1086/228631)

Brockmann D, Helbing D. 2013 The hidden geometry of complex, network-driven contagion phenomena. Science (80). 342, 1337-1342. (doi:10.1126/science.1245200)

Burnside WR, Brown JH, Burger O, Hamilton MJ, Moses M, Bettencourt LMA. 2012 Human macroecology: linking pattern and process in big-picture human ecology. Biol. Rev. 87, 194-208. (doi:10.1111/j.1469-185X.2011.00192.x)

Carlson CJ, Chipperfield JD, Benito BM, Telford RJ, O'Hara RB. 2020. Species distribution models are inappropriate for COVID-19. Nature Ecology and Evolution 4:770-771. DOI: 10.1038/s41559-020-1212-8. 
312

313

314

315

316

317

318

319

320

321

322

323

324

325

326

327

328

329

330

331

332

333

334

335

336

337

338

339

340

341

342

343

344

345

346

347

348

349

350

351

352

353

354

355
Chan KH, Peiris JSM, Lam SY, Poon LLM, Yuen KY, Seto WH. 2011 The effects of temperature and relative humidity on the viability of the SARS coronavirus. Adv. Virol. 2011. (doi:10.1155/2011/734690)

Chinazzi M, Davis JT, Ajelli M, Gioannini C, Litvinova M, Merler S, Pastore Y Piontti A, Mu K, Rossi L, Sun K, Viboud C, Xiong X, Yu H, Halloran ME, Longini IM, Vespignani A. 2020. The effect of travel restrictions on the spread of the 2019 novel coronavirus (COVID-19) outbreak. Science (New York, N.Y.) 9757:1-12. DOI: 10.1126/science.aba9757.

Csardi G, Nepusz T .2006. The igraph software package for complex network research. InterJournal, Complex Systems, 1695. http://igraph.org.

Dattilo W, Silva AC, Guevara R, McGregor-Fors I, Pontes S. 2020 COVID-19 most vulnerable Mexican cities lack the public health infrastructure to face the pandemic: a new temporally-explicit model. medRxiv , 1-13. (doi:10.1101/2020.04.10.20061192)

De Marco P, Diniz-Filho JAF, Bini LM. 2008 Spatial analysis improves species distribution modelling during range expansion. Biol. Lett. 4, 577-580. (doi:10.1098/rsbl.2008.0210)

Delamater PL, Street EJ, Leslie TF, Yang YT, Jacobsen KH. 2019 Complexity of the basic reproduction number (R0). Emerg. Infect. Dis. 25, 1-4. (doi:10.3201/eid2501.171901)

Dong E, Du H, Gardner L. 2020 An interactive web-based dashboard to track COVID-19 in real time. Lancet Infect. Dis. 20, 533-534. (doi:10.1016/S1473-3099(20)30120-1)

Doremalen NV, Bushmaker T, Munster VJ. 2013 Stability of middle east respiratory syndrome coronavirus (MERS-CoV) under different environmental conditions. Eurosurveillance 18, 1-4. (doi:10.2807/1560-7917.ES2013.18.38.20590)

Duan S-M, Zhao X-S, Wen R-F, Huang J-J, Pi G-H, Zhang S-X, Han J, Bi S-L, Ruan L, Dong X-P. 2003. Stability of SARS coronavirus in human specimens and environment and its sensitivity to heating and UV irradiation. Biomedical and environmental sciences : BES $16: 246-255$.

Enserink, M \& Kupferschmidt, K. (2020). Mathematics of life and death: How disease models shape national shutdowns and other pandemic policies. Science (https://www.sciencemag.org/news/2020/03/mathematics-life-and-death-how-diseasemodels-shape-national-shutdowns-and-other\#)

European Centre for Disease Prevention and Control (ECDC). COVID-19 - Situation update worldwide. Stockholm: ECDC; 1 Apr 2020. Available from: https://www.ecdc.europa.eu/en/geographical-distribution-2019-ncov-cases 
356

357

358

359

360

361

362

363

364

365

366

367

368

369

370

371

372

373

374

375

376

377

378

379

380

381

382

383

384

385

386

387

388

389

390

391

392

393

394

395

396

397

398

399

400

Fick SE, Hijmans RJ. 2017 WorldClim 2: new 1-km spatial resolution climate surfaces for global land areas. Int. J. Climatol. 37, 4302-4315. (doi:10.1002/joc.5086)

Gaunt ER, Hardie A, Claas ECJ, Simmonds P, Templeton KE. 2010 Epidemiology and clinical presentations of the four human coronaviruses 229E, HKU1, NL63, and OC43 detected over 3 years using a novel multiplex real-time PCR method. J. Clin. Microbiol. 48, 29402947. (doi:10.1128/JCM.00636-10)

Gilbert M, Pullano G, Pinotti F, Valdano E, Poletto C, Boëlle PY, D’Ortenzio E, Yazdanpanah Y, Eholie SP, Altmann M, Gutierrez B, Kraemer MUG, Colizza V. 2020. Preparedness and vulnerability of African countries against importations of COVID-19: a modelling study. The Lancet 395:871-877. DOI: 10.1016/S0140-6736(20)30411-6.

Grassly NC, Fraser C. 2008. Mathematical models of infectious disease transmission. Nature Reviews Microbiology 6:477-487. DOI: 10.1038/nrmicro1845.

Harbert RS, Cunningham SW, Tessler M. 2020. Spatial modeling cannot currently differentiate SARS-CoV-2 coronavirus and human distributions on the basis of climate in the United States. medRxiv:2020.04.08.20057281. DOI: 10.1101/2020.04.08.20057281.

Harris I, Jones PD, Osborn TJ, Lister DH. 2014 Updated high-resolution grids of monthly climatic observations - the CRU TS3.10 Dataset. Int. J. Climatol. 34, 623-642. (doi:10.1002/joc.3711)

International Air Transport Association. 2019. Annual Review(https://www.iata.org/contentassets/c81222d96c9a4e0bb4ff6ced0126f0bb/iataannual-review-2019.pdf)

Jaffe R, Vera MPO, Jaffe K. 2020. Globalized low-income countries may experience higher COVID-19 mortality rates. medRxiv:2020.03.31.20049122. DOI: 10.1101/2020.03.31.20049122.

John St. RK, King A, De Jong D, Bodie-Collins M, Squires SG, Tam TWS. 2005 Border screening for SARS. Emerg. Infect. Dis. 11, 6-10. (doi:10.3201/eid1101.040835)

Khalatbari-Soltani S, Cumming RG, Delpierre C, Kelly-Irving M. 2020. Importance of collecting data on socioeconomic determinants from the early stage of the COVID-19 outbreak onwards. Journal of epidemiology and community health:620-623. DOI: 10.1136/jech2020-214297.

Kraemer MUG, Yang CH, Gutierrez B, Wu CH, Klein B, Pigott DM, du Plessis L, Faria NR, Li R, Hanage WP, Brownstein JS, Layan M, Vespignani A, Tian H, Dye C, Pybus OG, Scarpino S V. 2020. The effect of human mobility and control measures on the COVID- 
401

402

403

404

405

406

407

408

409

410

411

412

413

414

415

416

417

418

419

420

421

422

423

424

425

426

427

428

429

430

431

432

433

434

435

436

437

438

439

440

441

442

443

444

445

446

19 epidemic in China. Science (New York, N.Y.) 497:493-497. DOI:

10.1126/science.abb4218.

Liu Y, Gayle AA, Wilder-Smith A, Rocklöv J. 2020. The reproductive number of COVID-19 is higher compared to SARS coronavirus. Journal of Travel Medicine 27:1-4. DOI:

10.1093/jtm/taaa021.

Legendre P, Lengedre L. Numerical Ecology. Elsevier Science.

Lowen AC, Mubareka S, Steel J, Palese P. 2007 Influenza virus transmission is dependent on relative humidity and temperature. PLoS Pathog. 3, 1470-1476. (doi:10.1371/journal.ppat.0030151)

Madotto A, Liu J. 2016 Super-Spreader Identification Using Meta-Centrality. Sci. Rep. 6, 1-10. (doi:10.1038/srep38994)

Murray KA, Olivero J, Roche B, Tiedt S, Guégan JF. 2018 Pathogeography: leveraging the biogeography of human infectious diseases for global health management. Ecography

(Cop.). 41, 1411-1427. (doi:10.1111/ecog.03625)

Nekola JC, White PS. 1999 The distance decay of similarity in biogeography and ecology. $J$. Biogeogr. 26, 867-878. (doi:10.1046/j.1365-2699.1999.00305.x)

Nishiura H, Kamiya K. 2011 Fever screening during the influenza (H1N1-2009) pandemic at Narita International Airport, Japan. BMC Infect. Dis. 11, 1-11. (doi:10.1186/1471-233411-111)

Openflights.org database. 2014. http://openflights.org/data.html. Accessed 20 March 2020

Poulin R. 2003 The decay of similarity with geographical distance in parasite communities of vertebrate hosts. J. Biogeogr. 30, 1609-1615. (doi:10.1046/j.1365-2699.2003.00949.x)

Pybus OG, Tatem AJ, Lemey P. 2015 Virus evolution and transmission in an ever more connected world. Proc. R. Soc. B Biol. Sci. 282, 1-10. (doi:10.1098/rspb.2014.2878)

Ribeiro SP, Dattilo W, Silva AC e, Reis AB, Goes-Neto A, Alcantara L, Giovanetti M, Couravital W, Fernandes GW, Azevedo VA. 2020. Severe airport sanitarian control could slow down the spreading of COVID-19 pandemics in Brazil. medRxiv:2020.03.26.20044370. DOI: $10.1101 / 2020.03 .26 .20044370$.

Sajadi MM, Habibzadeh P, Vintzileos A, Shokouhi S, Miralles-Wilhelm F, Amoroso A. 2020 Temperature and Latitude Analysis to Predict Potential Spread and Seasonality for COVID-19. SSRN Electron. J. , 6-7. (doi:10.2139/ssrn.3550308) 
447

448

449

450

451

452

453

454

455

456

457

458

459

460

461

462

463

464

465

466

467

468

469

470

471

472

473

474

475

476

477

478

479

480

481

482

483

484

485

486

487

488

489

490

491

492
Shaman J, Pitzer VE, Viboud C, Grenfell BT, Lipsitch M. 2010 Absolute humidity and the seasonal onset of influenza in the continental United States. PLoS Biol. 8.

(doi:10.1371/journal.pbio.1000316)

Stier AJ, Berman MG, Bettencourt LMA. 2020. COVID-19 attack rate increases with city size. arXiv.

Sun G., Matsui T., Kirimoto T., Yao Y., Abe S. .2017. Applications of Infrared Thermography for Noncontact and Noninvasive Mass Screening of Febrile International Travelers at Airport Quarantine Stations. In: Ng E., Etehadtavakol M. (eds) Application of Infrared to Biomedical Sciences. Series in BioEngineering. Springer, Singapore

Tan J, Mu L, Huang J, Yu S, Chen B, Yin J. 2005 An initial investigation of the association between the SARS outbreak and weather: With the view of the environmental temperature and its variation. J. Epidemiol. Community Health 59, 186-192. (doi:10.1136/jech.2004.020180)

Tian H, Sun Z, Faria NR, Yang J, Cazelles B, Huang S, Xu B, Yang Q, Pybus OG, Xu B. 2017. Increasing airline travel may facilitate co-circulation of multiple dengue virus serotypes in Asia. PLOS Neglected Tropical Diseases 11:e0005694. DOI: 10.1371/journal.pntd.0005694.

Wang J, Tang K, Feng K, Lv W. 2020 High Temperature and High Humidity Reduce the Transmission of COVID-19. SSRN Electron. J. , 1-19. (doi:10.2139/ssrn.3551767)

Warren DL, Cardillo M, Rosauer DF, Bolnick DI. 2014 Mistaking geography for biology: inferring processes from species distributions. Trends Ecol. $\{\&\}$ Evol. 29, 572-580. (doi:10.1016/j.tree.2014.08.003)

World Health Organization. 2020. Statement on the meeting of the International Health Regulations (2005) Emergency Committee regarding the outbreak of novel coronavirus (2019-nCoV). Retrieved from https:/www.who.int/news-room/detail/23-01-2020statement-on-the-meeting-of-the-international-health-regulations-(2005)-emergencycommittee-regarding-the-outbreak-of-novel-coronavirus-(2019-ncov)

Zhang R, Li Y, Zhang AL, Wang Y, Molina MJ. 2020. Identifying airborne transmission as the dominant route for the spread of COVID-19. Proceedings of the National Academy of Sciences:202009637. DOI: 10.1073/pnas.2009637117.

Zuk T, Rakowski F, Radomski JP. 2009 Probabilistic model of influenza virus transmissibility at various temperature and humidity conditions. Comput. Biol. Chem. 33, 339-343. (doi:10.1016/j.compbiolchem.2009.07.005) 
Figure 1

Air transportation network among 65 countries that had more than 100 cases and for which time series data had at least 30 days after the $100^{\text {th }}$ case.

Different colours represent modules of countries that are more connected to each other. Different sizes of each node represent the growth rate of COVID-19 estimated for each country. 


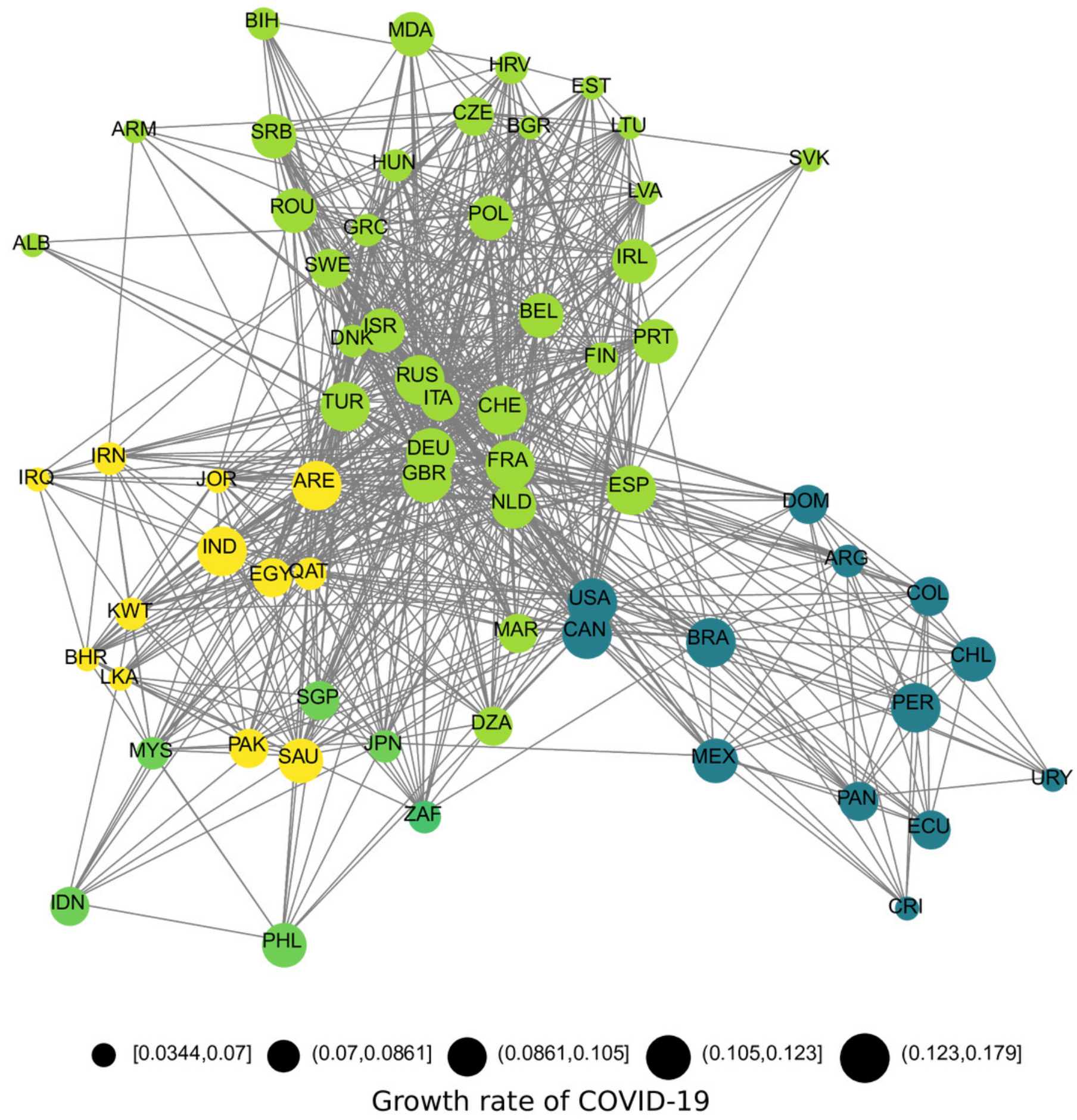




\section{Figure 2}

Geographical pattern of the early growth rate of COVID-19 in different countries. Growth rate is represented by the regression coefficient of the log growth series.

\section{Growth Rate}

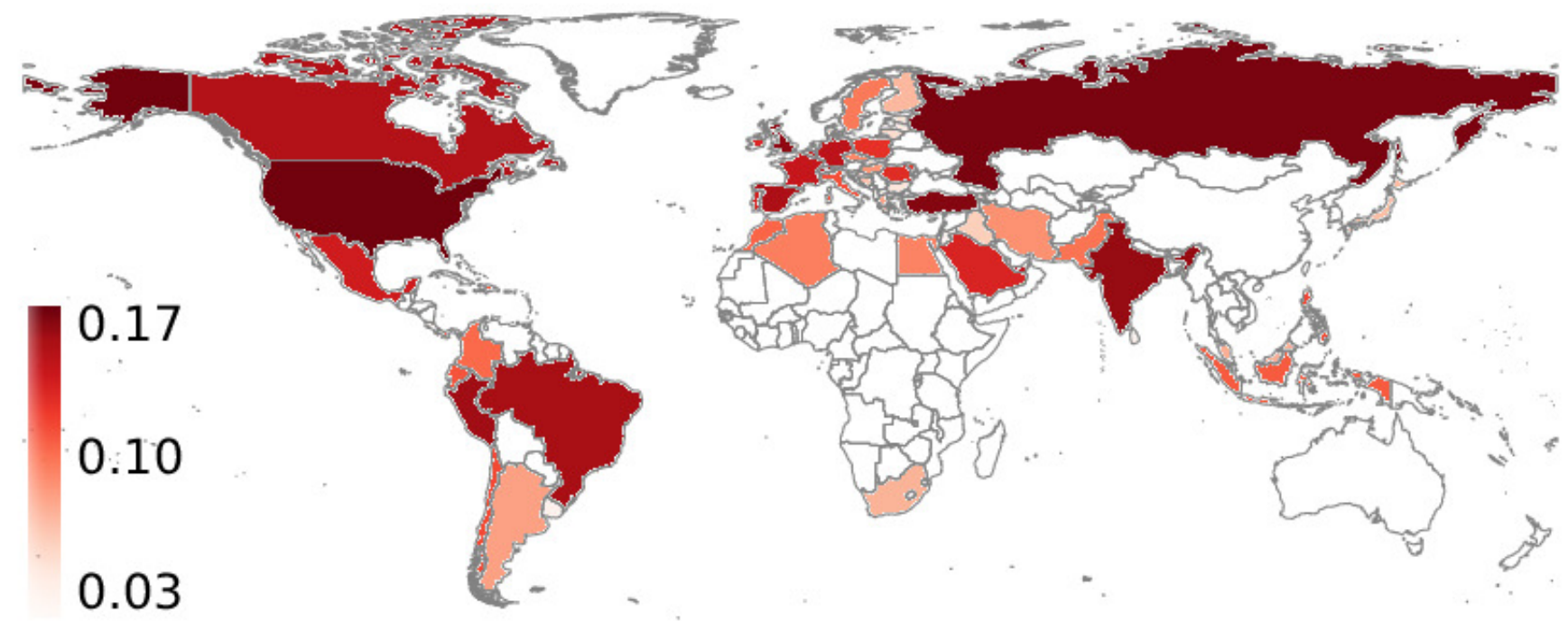




\section{Figure 3}

Spatial patterns of predictors and their relationship with COVID-19 growth rates.

Countries importance in the global transportation network $(\mathbf{A})$ and population size $(\mathbf{C})$ are strongly associated with early growth rates of covid-19 across the world (B and $\mathbf{D})$.

A Eigenvector Centrality

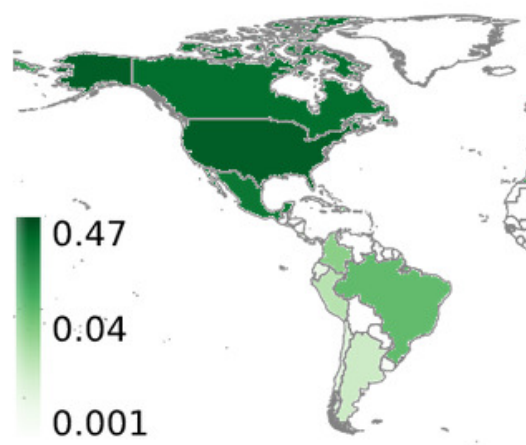

C Population Size

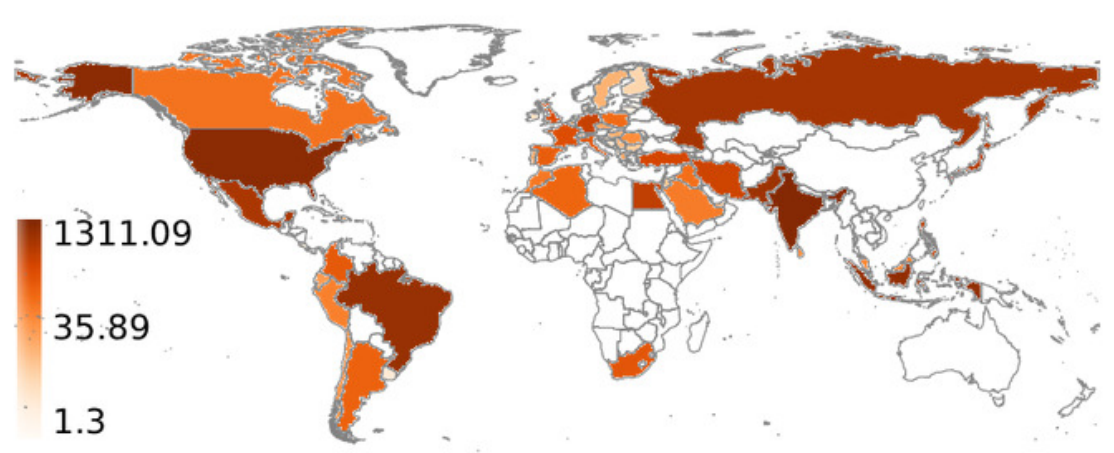

B
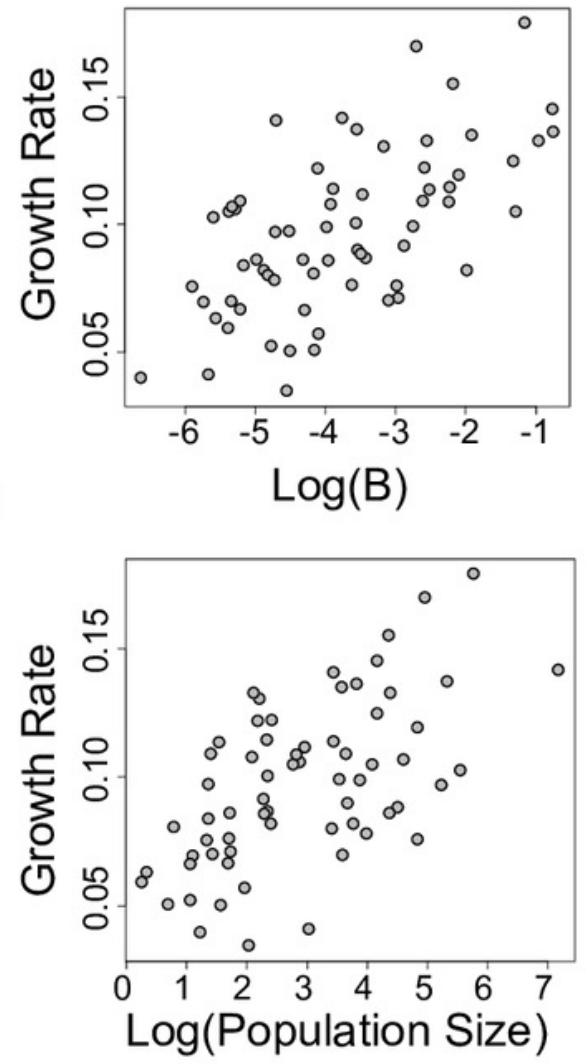


\section{Table 1 (on next page)}

Model statistics for all variables used in the study. 
1 Table 1. Model statistics for all variables used in the study.

\begin{tabular}{lccccc}
\hline & $\begin{array}{c}\text { Standardized } \\
\text { Estimate }\end{array}$ & Estimate & Std Error & t value & P-value \\
\hline Intercept & & 0.074 & 0.023 & 3.232 & 0.002 \\
Eigenvector Centrality & 0.387 & 0.009 & 0.003 & 2.812 & $\mathbf{0 . 0 0 6}$ \\
Gross National Income & 0.264 & 0.000 & 0.000 & 1.764 & 0.083 \\
Population Size & 0.519 & 0.011 & 0.002 & 4.487 & $<\mathbf{0 . 0 0 1}$ \\
Annual population growth & 0.096 & 0.003 & 0.004 & 0.658 & 0.513 \\
Heath investment & -0.168 & 0.000 & 0.000 & -1.140 & 0.259 \\
Mean Temperature & -0.208 & -0.001 & 0.000 & -1.695 & 0.095 \\
Mean Precipitation & 0.184 & 0.006 & 0.003 & 1.730 & 0.089 \\
\hline
\end{tabular}

2 